Communication

\title{
Effects of Experimental Warming and Canada Goldenrod Invasion on the Diversity and Function of the Soil Nematode Community
}

\author{
Guanlin $\mathrm{Li}^{1}{ }^{1}$, Jingquan Wang ${ }^{2}$, Jiaqi Zhang ${ }^{3}$, Yingnan $\mathrm{Li}^{4}{ }^{4}$, Enxi Liu ${ }^{1}$, Yuechen $\mathrm{Yu}^{2}{ }^{2}$, Babar Iqbal ${ }^{2}$, Zhicong Dai ${ }^{2}{ }^{\oplus}$, \\ Hui Jia ${ }^{2}$, Jian $\mathrm{Li}^{1, *}$ and Daolin $\mathrm{Du}^{2, *}$ \\ 1 Institute of Environmental Health and Ecological Security, School of Environment and Safety Engineering, \\ Jiangsu University, Zhenjiang 212013, China; liguanlin@ujs.edu.cn (G.L.); lexgxs@gmail.com (E.L.) \\ 2 School of the Environment and Safety Engineering, Jiangsu University, Zhenjiang 212013, China; \\ wangjingqvan@163.com (J.W.); yyc19990930@163.com (Y.Y.); babar@ujs.edu.cn (B.I.); \\ daizhicong@163.com (Z.D.); jiahuiboru@126.com (H.J.) \\ 3 Ministry of Education Key Laboratory for Ecology of Tropical Islands, Key Laboratory of Tropical Animal and \\ Plant Ecology of Hainan Province, College of Life Sciences, Hainan Normal University, Haikou 571158, China; \\ zhangjiaqi_solana@163.com \\ 4 Department of Environmental Design, School of Arts, Jiangsu University, Zhenjiang 212013, China; \\ lyn48512@hotmail.com \\ * Correspondence: 1j060404002@126.com (J.L.); dd1@ujs.edu.cn (D.D.); \\ Tel./Fax: +86-511-8879-0955 (J.L.); +86-511-8879-1200 (D.D.)
}

\section{check for} updates

Citation: Li, G.; Wang, J.; Zhang, J.; Li, Y.; Liu, E.; Yu, Y.; Iqbal, B.; Dai, Z.; Jia, H.; Li, J.; et al. Effects of Experimental Warming and Canada Goldenrod Invasion on the Diversity and Function of the Soil Nematode Community. Sustainability 2021, 13, 13145. https://doi.org/10.3390/ su132313145

Academic Editor: Panayiotis Dimitrakopoulos

Received: 31 October 2021

Accepted: 24 November 2021

Published: 27 November 2021

Publisher's Note: MDPI stays neutral with regard to jurisdictional claims in published maps and institutional affiliations.

Copyright: (C) 2021 by the authors. Licensee MDPI, Basel, Switzerland. This article is an open access article distributed under the terms and conditions of the Creative Commons Attribution (CC BY) license (https:/ / creativecommons.org/licenses/by/ $4.0 /)$.
Abstract: Both global warming and alien plant invasion can affect the biotic communities in the soil. Most studies are focused on the soil microbial community, but little is known about how global warming, along with alien plant invasion, affects the diversity and function of the soil nematode community. In this study, the individual and interactive effects of experimental warming and Canada goldenrod (Solidago canadensis L.) invasion on soil nematode communities were measured. Experimental air warming, in combination with different levels of $S$. canadensis invasion, were applied. The results showed that $S$. canadensis invasion significantly increased chao1, maturity, and structure indexes of the nematode community by $31.44 \%, 25.57 \%$, and $329.3 \%$, respectively, and decreased the basal index by $48.70 \%$ (all $p<0.05$ ). Only the Simpson index was affected by the interaction between warming and S. canadensis invasion. Warming enhanced the S. canadensis invasion effect on the soil nematode community. The changes in nematode community were correlated with shifts in nutrient availability and resource stoichiometry, as well as microbes in the soil. These findings demonstrated that global warming and S. canadensis invasion may, directly and indirectly, alter the soil nematode community, which may considerably affect the functioning of underground food webs.

Keywords: global warming; alien plant invasion; soil nematode; soil nutrient availability and stoichiometry; Solidago canadensis L.

\section{Introduction}

It is well known that many soil ecosystem functions are mediated by biodiversity in natural ecosystem [1]. Interactions between plants and soil animals are drivers of soil ecological processes and the backbone of soil biodiversity [2]. The plant-animal interactions can be complex, since the changes in vegetation community can cause shifts in simultaneous interactions with soil animals and a mutualistic-antagonistic gradient [3]. Hence, understanding the complexities of the plant-animal interactions and the ecosystem consequences of disrupting their diversity in the advent of climate change have become important research topics.

Soil nematodes are one of the important parts of soil biodiversity and are the animals with the richest biodiversity and the most diverse functions in the soil [4]. Soil nematodes 
can participate in soil ecological processes and have a significant effect on soil organic matter decomposition, nutrient transformation, and energy transfer [5-8]. Numerous studies have demonstrated that global warming can directly or indirectly affect the soil nematode community [5]. For example, it was reported that global warming altered the soil nematode community structure and reduced the nematode community abundance and composition in the agricultural and grass ecosystems $[9,10]$. However, in the desert ecosystem, the warming effect was not observed [11]. In addition, other studies have shown that the response of soil nematodes to warming is not related to the warming amplitude, but is negatively correlated with the duration of warming, mainly because warming reduces the available water content in the soil and restricts the growth and reproduction of organisms [12,13]. These findings suggested that the response of the soil nematode community to warming may be influenced by the ecosystem type and local climatic conditions. Thus, understanding the mechanistic framework by which the global warming impact soil nematode community is crucial for predicting and maintaining natural ecosystem functionality and biodiversity in the warming world.

One of the profound consequences of alien plant invasion is a negative effect on the biotic community in the soil. Similar to the alien plant invasive effect on soil microbial communities, alien plant invasion can affect the richness, diversity, and characteristic trophic groups of soil nematode community via varied mechanism [14,15]. Zhang et al. (2019) found that Spartina alterniflora invasion can homogenize nematode communities in wetland soil, because Spartina alterniflora invasion induced the extraordinary homogenization of soil microbial communities [16]. Lazzaro found that Robinia pseudoacacia invasion altered nematode communities by changing the soil microenvironment via substrate input into the soil. (i.e., soil moisture, pH, nutrient) [17]. However, most of the studies described the alterations in the nematode community induced by alien plant invasion from the perspective of the soil microbial community, or the perspective of the soil microenvironment, but did not explain the effect of the soil microenvironmental and microbial indicators on the changes in the nematode community $[18,19]$. Furthermore, compared to the soil microbial community, the soil nematode response to alien plant invasion is poorly understood. The limited knowledge of soil nematode responses to alien plant invasion may pose challenges to the accurate prediction of the underlying negative effect on the processes and functions of soil ecosystem, such as the carbon cycle, and mitigation of its contribution to global warming.

Canada goldenrod (Solidago canadensis L.), introduction from North America in 1935, has become one of the profound consequences of invasive alien plants in China [20,21]. Numerous studies have revealed that $S$. canadensis invasion seriously threatens the biodiversity and ecological functions of the invaded ecosystems. Thus, the objective of the present study was to investigate the patterns and its drivers of the soil nematode community following the combined effect of global warming and S. canadensis invasion. To test this, an artificial warming simulation and S. canadensis invasion experiment was conducted. Here, the study was predicated upon the following hypothesis: warming and S. canadensis invasion and their interaction will alter the diversity and function of the soil nematode community via inducing changes in both soil microenvironment and microbes. The response patterns of the soil nematode community to global warming, along with S. canadensis invasion, revealed in the present study will improve the understanding of the alterations in biota communities during alien plant invasion processes under global warming.

\section{Materials and Methods}

\subsection{Study Design}

The study was conducted in a greenhouse on the Jiangsu University campus $\left(32^{\circ} 12^{\prime} \mathrm{N}\right.$, $119^{\circ} 30^{\prime} \mathrm{E}$ ) in Zhenjiang City, China. To avoid the influence of $S$. canadensis invasion on soil's physical, chemical, and biological characteristics, the experimental soil was obtained from a green space without $S$. canadensis invasion from the Jiangsu University campus in April 2020. The collected soil samples were sieved and placed in plastic pots $(17 \mathrm{~cm}$ top diameter, $15 \mathrm{~cm}$ bottom diameter, and $18 \mathrm{~cm}$ height). S. canadensis and the native 
plant Solidago decurrens L. were cultivated in the soil in April 2020. After two months of cultivation, S. canadensis and S. decurrens seedlings of similar sizes were transplanted into pots.

Briefly, the experiment was established on 15 June 2020, and ended on 13 January 2021. The experiment consisted of two levels of air warming treatment: warmed air temperature by $3^{\circ} \mathrm{C}(\mathrm{W})$ and natural air temperature unwarmed as the control (U). It was crossed with three levels of $S$. canadensis invasion treatment: non-invasion (NI), middle invasion (MI), and complete invasion (CI). Thus, there were a total of six treatments that were performed in triplicate. Warming treatments were applied with the thermostat and heaters. S. canadensis invasion treatments were set up by simulating the natural S. canadensis invasion process by planting different ratios of $S$. canadensis to $S$. decurrens seedlings in a pot (a total of two seedlings planted in each pot), based on the substitution of space for time method: NI treatment with two S. decurrens seedlings, MI treatment with one S. decurrens seedling and one $S$. canadensis seedling, and CI treatment with two $S$. canadensis seedlings [22]. All pots were placed in the greenhouse and watered every 2-3 days.

\subsection{Soil Sample Collection and Preparation}

The topsoil $(0-10 \mathrm{~cm})$ was collected using a soil corer $(2.0 \mathrm{~cm}$ diameter $)$ on 13 January 2021 and divided into three parts after mixing. One part was to extract the soil nematode within $48 \mathrm{~h}$ after sampling, one part was temporarily stored in a $4{ }^{\circ} \mathrm{C}$ refrigerator for analysis of soil microbial properties, and the last portion was air-dried at room temperature for analysis of physical and chemical properties of the soil.

\subsection{Soil Property Measurements}

The soil moisture content (SM) was measured by machine drying, and the mass loss was calculated after $72 \mathrm{~h}$ of drying at $105^{\circ} \mathrm{C}$. The $\mathrm{pH}$ value was measured by a $\mathrm{pH}$ meter in a 5:1 ratio of deionized water to air-dried soil. The contents of soil dissolved organic carbon (DOC) and nitrogen (DON) were measured by the methods in Li et al. (2020) [23]. Determination of soil available phosphorus (SAP) was conducted by molybdate colorimetry [24,25]. Soil inorganic nitrogen is the sum of nitrate nitrogen and ammonium nitrogen, and were measured by Miranda et al. and Mulvaney's method, respectively [26,27]. Determination of soil microbial biomass carbon $(\mathrm{MBC})$ and nitrogen (MBN) was by chloroform fumigation $[28,29]$. Determination of soil microbial biomass phosphorus (MBP) was by chloroform fumigation extraction and molybdate colorimetry $[24,25,28,29]$.

\subsection{Soil Nematode Extraction, Classification, and Analyses}

Soil nematodes were extracted from $80 \mathrm{~g}$ of soil from each subsample using the Baermann funnel method [30]. Nematode community composition classification was conducted using molecular tools on all the extracted soil nematodes. Nematode DNA in the soil was extracted using the PowerLyzer Power-Soil®DNA Isolation Kit (Mo Bio Laboratories, Carlsbad, CA, USA) according to the manufacturer's instructions. To generate amplicons, primers NF1 and 18Sr2b were used in a pre-amplification step followed by amplification in a semi-nested procedure. NF1 and $18 \mathrm{Sr} 2 \mathrm{~b}$ were tag-encoded using the forward primer GGTGGTGCATGGCCGTTCTTAGTT and the reverse primer TACAAAGGGCAGGGACGTAAT. The obtained sequences were further grouped into operational taxonomic units. Taxonomic classification of each operational taxonomic unit was obtained by classifying alignments against the SILVA Release 123 database.

\subsection{Statistical Analyses}

In the present study, we calculated seven ecological function indexes to evaluate the changes in the taxon diversity, richness, and function of soil nematode communities induced by the treatments. In detail, the taxon diversity and richness of soil nematode communities was calculated by using the Simpson and chao1 indexes. The maturity index was calculated according the vital parameters and ecological requirements of nematodes [31]. 
The enrichment, structure, and channel indexes were calculated based on Ferris et al. (2001) [32], which indicates the abundance and activity of primary detrital consumers, the complexity and stability of the food web, and the predominant decomposition pathways of the food web, respectively [33].

Principal component analysis (PCA) was performed to identify differences in soil properties among different soil samples. Generalized linear model (GLM) and Fisher's least significance difference test $(p<0.05)$ were performed to evaluate the differences in the effects of warming and S. canadensis invasion on the ecological function indices of the soil nematode community. Redundancy analysis (RDA) and a permutational multivariate ANOVA (PERMANOVA) were used to analyze differences in the ecological function indices of the soil nematode community in relation to soil environmental variables. Furthermore, RDA results were used for variance partitioning analysis (VPA) to further evaluate the relative importance of soil environmental variables in the changes of the nematode community. The partial least squares path model (PLS-PM) was used to establish the possible paths of warming and S. canadensis invasion on the diversity and function of the nematode community in the soil. All analyses were performed using R software version 4.1.1 [34].

\section{Results}

\subsection{Soil Properties}

Principal component analysis (PCA) showed that the two-dimensional PCA of the soil properties could explain $66 \%$ of the total variance for all samples. Moreover, PCA showed a clear shift for soil properties along the first axis of PCA induced by warming treatment (Figure 1). Soil $\mathrm{pH}(p<0.01)$, dissolved organic carbon (DOC; $p<0.05)$, dissolved organic nitrogen (DON; $p<0.05)$, and inorganic nitrogen (SIN; $p<0.05)$ were significantly affected by warming. Compared with unwarmed treatment pots, the $\mathrm{pH}$ changed by $6.66 \%$, $1.87 \%$, and $-1.74 \%$, in non-invasion (NI), middle invasion (MI), and complete invasion (CI) treatment pots, respectively. In addition, warming altered soil DOC and DON by $24.50 \%$ and $-10.81 \%, 14.01 \%$ and $66.39 \%$, and $41.07 \%$ and $64.70 \%$, while warming decreased SIN by $-60.96 \%,-18.64 \%$, and $-44.57 \%$ in the NI, MI, and CI treatment pots under unwarmed treatment, respectively (Figure S1 in Supplementary Materials).

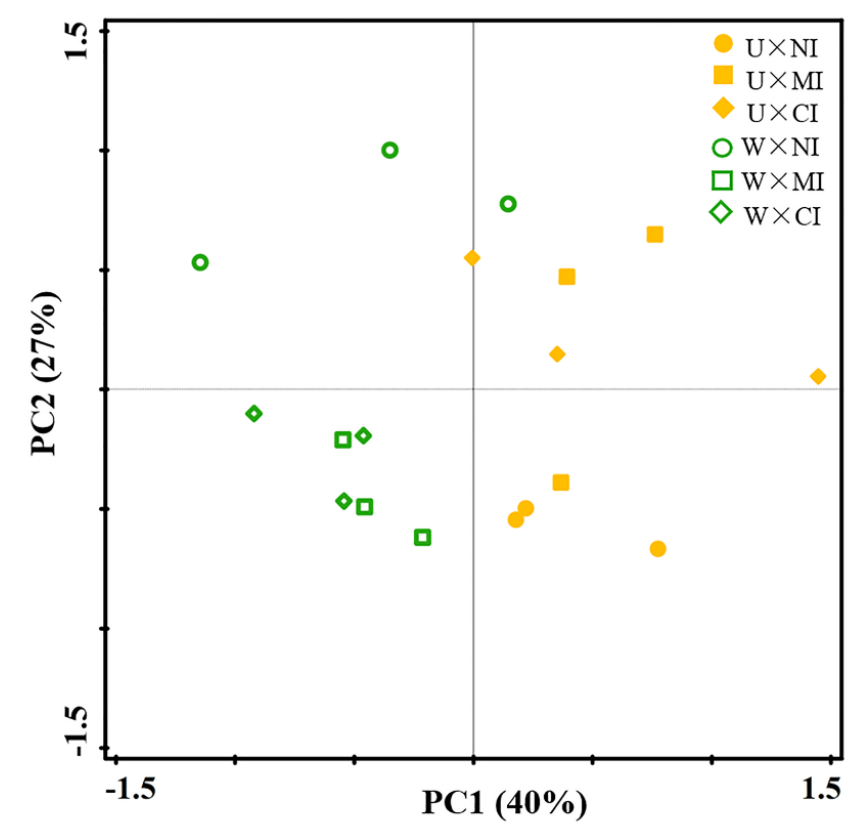

Figure 1. Principal component analysis (PCA) based on soil properties. $\mathrm{W} \times \mathrm{NI}=$ warming and non-invasion treatment; $\mathrm{W} \times \mathrm{MI}=$ warming and middle invasion treatment; $\mathrm{W} \times \mathrm{CI}=$ warming and complete invasion treatment; $\mathrm{U} \times \mathrm{NI}=$ unwarmed and non-invasion treatment; $\mathrm{U} \times \mathrm{MI}=$ unwarmed and middle invasion treatment; $\mathrm{U} \times \mathrm{CI}=$ unwarmed and complete invasion treatment. 


\subsection{Soil Nematode Diversity and Functional Indices}

S. canadensis invasion significantly increased the chao1 index $(p<0.05)$, maturity index $(p<0.05)$, and structure index $(p<0.01)$ of nematode communities, which were $31.44 \%, 25.57 \%$, and $329.3 \%$, respectively, and significantly decreased the basal index by $48.70 \%(p<0.05)$. Moreover, the Simpson index and structure index were also affected by the interaction between warming and S. canadensis invasion (all $p<0.05)$. Compared with NI soil, the Simpson index and basal index in CI soil decreased by 60.68 and $69.84 \%$ under warming treatment, while they decreased by $58.80 \%$ and $18.28 \%$ under unwarmed treatment. In addition, the chao1 index, maturity index, structure index, and enrichment index in CI soil were $41.57 \%$ and $20.94 \%, 38.11 \%$ and $13.98 \%, 287.1 \%$ and $88.99 \%$, and $161.9 \%$ and $24.67 \%$ higher than those in NI soil under warming and unwarmed treatment, respectively. The channel index in the warming treatment pots were higher than in the unwarmed treatment pots (Table 1).

Table 1. The ecological function indexes of the soil nematode community for each treatment, presented as the mean \pm standard error $(n=3)$.

\begin{tabular}{|c|c|c|c|c|c|c|c|}
\hline & \multicolumn{3}{|c|}{ Unwarmed } & \multicolumn{3}{|c|}{ Warming } & \multirow{2}{*}{$\begin{array}{c}\text { Main Effects } \\
\text { and } \\
\text { Interactions }\end{array}$} \\
\hline & NI & MI & CI & NI & MI & CI & \\
\hline Simpson & $4.11 \pm 0.09 \mathrm{abc}$ & $2.50 \pm 0.29 c$ & $6.53 \pm 1.06 c$ & $6.00 \pm 0.50 \mathrm{ab}$ & $3.93 \pm 1.49 \mathrm{bc}$ & $2.36 \pm 0.63 c$ & $W \times I^{* *}$ \\
\hline Chao1 & $10.67 \pm 1.67 \mathrm{bc}$ & $9.33 \pm 1.20 \mathrm{bc}$ & $12.90 \pm 0.92 \mathrm{ab}$ & $11.07 \pm 1.55 \mathrm{bc}$ & $8.83 \pm 1.09 c$ & $15.67 \pm 0.83 a$ & $\mathrm{I}^{* *}$ \\
\hline Maturity Index & $2.16 \pm 0.07 \mathrm{bc}$ & $2.62 \pm 0.16 \mathrm{a}$ & $2.46 \pm 0.23 a b$ & $1.99 \pm 0.02 \mathrm{c}$ & $2.14 \pm 0.05 b c$ & $2.75 \pm 0.21 \mathrm{a}$ & I* \\
\hline Basal Index & $57.53 \pm 6.12 \mathrm{ab}$ & $31.92 \pm 7.26 \mathrm{~b}$ & $47.01 \pm 21.23 b$ & $82.78 \pm 5.57 a$ & $53.36 \pm 9.28 \mathrm{ab}$ & $24.97 \pm 6.90 b$ & $I^{*}$ \\
\hline $\begin{array}{l}\text { Enrichment } \\
\text { Index }\end{array}$ & $25.94 \pm 10.07 a$ & $33.55 \pm 6.62 \mathrm{a}$ & $32.34 \pm 15.02 \mathrm{a}$ & $15.35 \pm 6.41 \mathrm{a}$ & $28.83 \pm 15.23 a$ & $40.20 \pm 1.38 \mathrm{a}$ & ns \\
\hline Structure Index & $24.68 \pm 9.112 \mathrm{~cd}$ & $61.67 \pm 9.70 \mathrm{ab}$ & $\begin{array}{c}46.65 \pm \\
19.46 \mathrm{abc}\end{array}$ & $2.33 \pm 1.25 \mathrm{~d}$ & $30.24 \pm 0.61 \mathrm{bcd}$ & $69.33 \pm 9.78 \mathrm{a}$ & $I^{* *}$ \\
\hline Channel Index & $100.00 \pm 0.00 \mathrm{a}$ & $100.00 \pm 0.00 \mathrm{a}$ & $100.00 \pm 0.00 \mathrm{a}$ & $99.38 \pm 0.62 \mathrm{a}$ & $85.48 \pm 14.52 \mathrm{a}$ & $79.63 \pm 14.99 a$ & ns \\
\hline
\end{tabular}

$\mathrm{NI}=$ non-invasion treatment; $\mathrm{MI}=$ middle invasion treatment; $\mathrm{CI}=$ complete invasion treatment, $\mathrm{W}$ = warming treatment; $\mathrm{I}=$ invasion treatment. Values followed by a different letter are significantly different to each other $(p<0.05)$. ns= significant at the level of $p>0.05$,

$*$ significant at the level of $p<0.05$, and ${ }^{* *}=$ significant at the level of $p<0.01$.

\subsection{Relationship among Soil Properties and Ecological Function Indexes of Soil Nematode Community}

The redundancy analysis (RDA) results showed that ecological function indexes of the soil nematode community could explain $46.11 \%$ of the total variance in different warming and S. canadensis invasion for all samples (Figure 2). According to RDA results, $\mathrm{pH}$ and microbial biomass nitrogen (MBN) had a positive effect on $\mathrm{BI}$ and $\mathrm{CI}$, the ratio of microbial biomass carbon (MBC) to MBN had a negative effect on SI, and DOC, DON, and the ratio of DON to soil available phosphorus (SAP) had the greatest influence on EI (Figure 3). At the same time, variance partitioning analysis (VPA) revealed that the soil's physical and chemical properties, nutrient properties, and microbial properties explained $28 \%$, $33 \%$, and $46 \%$ of the changes in the soil nematode community ecological function indexes, respectively (Figure 3 ).

The PLS-PM model was established for path analysis of the soil nematode community, and it was found that warming and S. canadensis invasion significantly affected the soil nematode community (Figure 4a). On the one hand, warming affected soil physicochemical properties (e.g., moisture content and $\mathrm{pH}$ ), soil nutrient properties, and soil microbial properties and significantly influenced the nematode community. On the other hand, S. canadensis invasion significantly influenced the nematode community, and the capacity of warming and S. canadensis invasion on the influence of soil nematode community functional indexes were 0.196 and 0.594 , respectively (Figure $4 b$ ). 


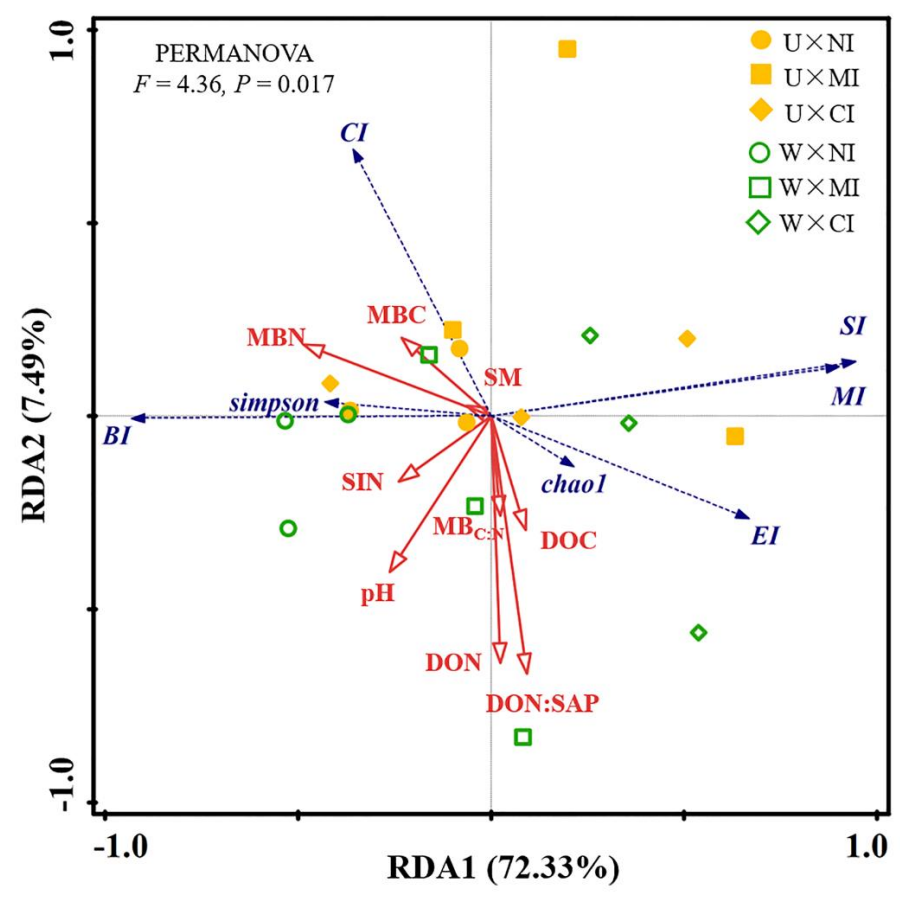

Figure 2. Result of redundancy analysis (RDA) and permutational multivariate analysis of variance (PERMANOVA) based on soil nematode community ecological function indexes and soil properties. $\mathrm{W} \times \mathrm{NI}=$ warming and non-invasion treatment; $\mathrm{W} \times \mathrm{MI}=$ warming and middle invasion treatment; $\mathrm{W} \times \mathrm{CI}=$ warming and complete invasion treatment; $\mathrm{U} \times \mathrm{NI}=$ unwarmed and non-invasion treatment; $\mathrm{U} \times \mathrm{MI}=$ unwarmed and middle invasion treatment; $\mathrm{U} \times \mathrm{CI}=$ unwarmed and complete invasion treatment. $\mathrm{MI}=$ maturity index; $\mathrm{EI}=$ enrichment index; $\mathrm{BI}=$ basal index; $\mathrm{SI}=$ structure index; $\mathrm{CI}=$ channel index $\mathrm{SM}=$ soil moisture; $\mathrm{DOC}=$ soil dissolved organic carbon; $\mathrm{DON}=$ dissolved organic nitrogen; $\mathrm{DON}$ : $\mathrm{SAP}=$ the ratio of dissolved organic nitrogen to available phosphorus; $\mathrm{SIN}$ = inorganic nitrogen; $\mathrm{MBC}=$ microbial biomass carbon; $\mathrm{MBN}=$ microbial biomass nitrogen .

Soil physical and chemical properties
Soil nutrient properties

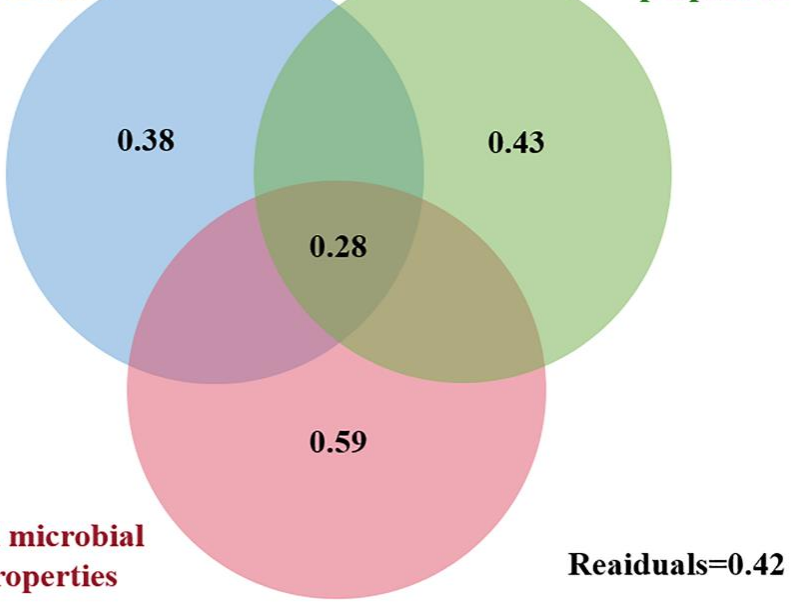

Figure 3. Results of variation partitioning analysis (VPA) showing the effects of the soil's physical and chemical properties, soil nutrient properties, and soil microbial properties on soil nematode community ecological function indexes. Soil's physical and chemical properties include soil moisture and $\mathrm{pH}$; soil nutrient properties include soil dissolved organic carbon, dissolved organic nitrogen, the ratio of dissolved organic carbon to available phosphorus, and inorganic nitrogen; Soil microbial properties include microbial biomass carbon, microbial biomass nitrogen, and the ratio of microbial biomass carbon to microbial biomass nitrogen. 
(a)

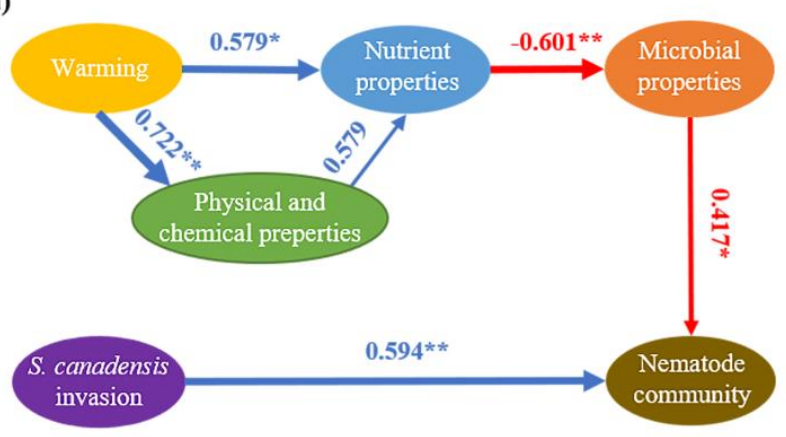

Gof $=\mathbf{0 . 5 0 4}$

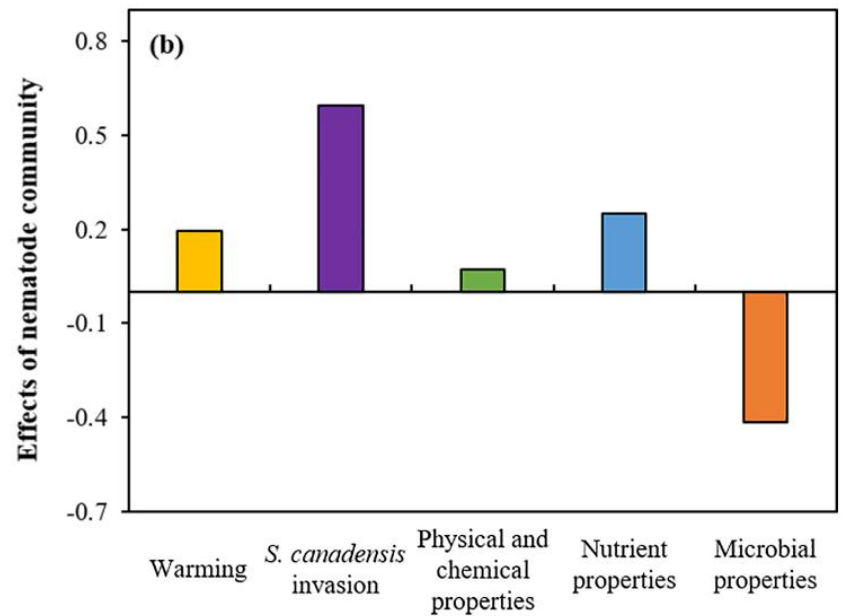

Figure 4. (a) Cascading relationships of the soil nematode community with soil properties among treatments and (b) each unit has a total effect on soil nematode community. Partial least squares path modeling (PLS-PM) disentangling major pathways of the influences of soil properties and treatments on the soil nematode community. Red and blue arrows indicate positive and negative flows of causality. ${ }^{*}=$ significant at the level of $p<0.05$, and ${ }^{* *}=$ significant at the level of $p<0.01$.

\section{Discussion}

Studies have demonstrated that climate change (e.g., global warming, altered precipitation patterns) can, directly and indirectly, alter the biodiversity of the aboveground vegetation community $[35,36]$. The changes in vegetation community would further induce shifts in belowground soil biota (e.g., animals, microbes) and biodiversity via various mechanisms [37,38]. Besides this, plant invasion also has detrimental effects on the biodiversity of soil biota by changing the substrate (e.g., litter, root exudates) input into soil [39]. In addition, Song et al. (2020) found that warming could enhance the plant invasion effect on soil microbial communities [40]. The soil nematode, as an important component of soil biota, can affect the soil ecosystem functions and processes. However, the knowledge of climate change and plant invasion effects, as well as their interaction, on soil nematode was limitation.

Previous studies showed that soil temperature and aboveground vegetation community could affect the growth, reproduction, and community composition of soil nematodes. Thus, we originally hypothesized that warming and S. canadensis invasion and their interaction will alter the soil nematode community via induced changes in both soil microenvironment and microbial biomass. In contrast to this prediction, warming was shown to indirectly affect the soil nematode community (Table 1, Figure 4a). This finding was inconsistent with some previous studies that showed warming can directly affect the growth, reproduction, and community composition of soil nematodes, as well as the soil microbial community $[9,41,42]$. In the present study, warming affected soil environmental conditions (moisture, $\mathrm{pH}$, nutrient) and microbial biomass (Figure 1), thereby indirectly altering the diversity and function of the soil nematode community (Figure 4a), which confirmed that soil status is significantly correlated with the nematode community $[43,44]$.

Some studies have indicated that alien invasive plants have a certain inhibitory effect on soil nematode communities. For example, Ren and Bal et al. (2005) compared the differences in soil nematode communities between invasive and non-invasive sites of Heracleum Sosnowskyi and found that Heracleum Sosnowskyi invasion led to a decrease in nematode abundance and species diversity [15]. Similarly, Lazzaro et al. (2018) found that soil nematode community richness was reduced in invaded region [17]. The alien plant invasive effects may be related to the invasion-induced alterations in the soil microbial community and vegetational community in the invaded region, since some of nematode feed on the microbes and plants [45]. In the previous studies, we found that $S$. canadensis invasion can alter the metabolism and structure of the microbial community as well as 
vegetational community $[21,46]$. Thus, the observed inhibitory effect of $S$. canadensis invasion on soil nematode communities may be due to the $S$. canadensis invasion-induced alterations in soil microbes and vegetational community.

Interestingly, less interaction effects of warming and S. canadensis invasion on the soil nematode community were observed (Table 1). However, we found that warming enhanced the destruction effects of $S$. canadensis invasion on the soil nematode community (Table 1). Since the channel index indicates the decomposition path of the food web, the decrease in the channel index indicates the decomposition path of the food web gradually changed from fungal decomposition to bacterial decomposition [47]. In the present study, the inhibition effects of $S$. canadensis invasion on channel index under warming treatments were more drastic than under unwarmed treatments. These findings revealed that warming increased the inhibition of $S$. canadensis invasion on the fungal community, which was in line with Anthony et al. (2020) who found that warming enhanced the inhibitory effect of invasive plants on soil fungal communities [48]. Moreover, the lowest value of basal index and the highest value of Simpson, maturity, enrichment and structure indexes were founded at the warming and complete invasion treatment among all the treatments (Figure 2). These results indicate that warming leads to decreased diversity of soil nematode communities and makes soil nematode favor a K-selection strategy, indicating that warming would greatly strengthen the destruction of the nematode communities by invasive plants. Combining the present results with others, it was found that warming can enhance the negative effects of plant invasion on the soil biota community.

\section{Conclusions}

By an artificial warming simulation and S. canadensis invasion experiment, we studied the response mechanism of the soil nematode community to $S$. canadensis invasion under global warming. On the one hand, the nematode community can be directly damaged by S. canadensis invasion, which reduces the basic components of the nematode community and damages the soil food web. On the other hand, warming can also affect the nematode community by affecting soil nutrients and microbial biomass. In this study, we also found that warming enhances the destruction of nematode communities by $S$. canadensis invasion. However, this study was only conducted over seven months and experienced a growing season of invasive plants. It is not clear whether the structural changes in the nematode community affect the survival of invasive plants under the condition of continuous plant invasion, which needs to be further studied.

Supplementary Materials: The following are available online at https:/ / www.mdpi.com/article / 10.3390 / su132313145/s1, Figure S1: The influence of warming and Canada goldenrod invasion on soil properties.

Author Contributions: Conceptualization, G.L., J.L. and D.D.; methodology, G.L., J.W., J.Z. and D.D.; software, E.L.; investigation, J.W., Y.Y. and B.I.; data curation, G.L., J.W. and Y.Y.; writing—original draft preparation, G.L. and J.W.; writing—review and editing, Y.L., B.I., G.L. and D.D.; visualization, J.W., Y.L. and H.J.; funding acquisiti. All authors have read and agreed to the published version of the manuscript.

Funding: This research was funded by the National Natural Science Foundation of China [31800342, 31770446,32071521], the China Postdoctoral Science Foundation [2019M651720], the Talent Project from the "Double-Entrepreneurial Plan" in Jiangsu Province, the Jiangsu University Foundation, and the Scientific Research Foundation for Advanced Talents of Hainan Normal University [RC2100004377].

Acknowledgments: We are grateful to Zhiyuan $\mathrm{Hu}$, Sushu Cui, Xiaoxun Zhao, and Kangwei Shi for their help with the experiment during the study period. We are also grateful to the editor and one anonymous referee for providing valuable comments.

Conflicts of Interest: The authors declare no conflict of interest. 


\section{References}

1. Schleuning, M.; Frund, J.; Garcia, D. Predicting ecosystem functions from biodiversity and mutualistic networks: An extension of trait-based concepts to plant animal interactions. Ecography 2015, 38, 380-392. [CrossRef]

2. Del-Claro, K.; Torezan-Silingardi, H.M. Plant-Mediated Above-Belowground Interactions: A Phytobiome Story. In Plant-Animal Interactions Source of Biodiversity; Springer Nature Switzerland: Cham, Switzerland, 2021; pp. 205-232. [CrossRef]

3. Krupa, J.J.; Hopper, K.R.; Harwood, J.D. Plant animal interactions between carnivorous plants, sheetweb spiders, and groundrunning spiders as guild predators in a wet meadow community. Ecol. Evol. 2020, 10, 4762-4772. [CrossRef]

4. Wilschut, R.A.; Geisen, S. Nematodes as Drivers of Plant Performance in Natural Systems. Trends Plant Sci. 2021, 26, 237-247. [CrossRef]

5. Neher, D.A. Role of nematodes in soil health and their use as indicators. J. Nematol. 2001, 33, 161-168.

6. Hu, C.; Xia, X.G.; Han, X.M.; Chen, Y.F.; Qiao, Y.; Liu, D.H.; Li, S.L. Soil nematode abundances were increased by an incremental nutrient input in a paddy-upland rotation system. Helminthologia 2018, 55, 322-333. [CrossRef] [PubMed]

7. Gupta, D.; Bhandari, S.; Bhusal, D.R. Variation of nematode indices under contrasting pest management practices in a tomato growing agro-ecosystem. Heliyon 2019, 5, e02621. [CrossRef] [PubMed]

8. Maina, S.; Karuri, H.; Ng'endo, R.N. Nematode metabolic footprints, ecological and functional indices in tropical maize-beans agro-ecosystems under different farming practices. Acta Oecol. 2020, 108, 103622. [CrossRef]

9. Guo, X.H.; Endler, A.; Poll, C.; Marhan, S.; Ruess, L. Independent effects of warming and altered precipitation pattern on nematode community structure in an arable field. Agric. Ecosyst. Environ. 2021, 316, 107467. [CrossRef]

10. Coffey, V.; Otfinowski, R. Legacies of afforestation on soil nematode community composition, structure, and diversity in a northern Canadian prairie. Plant Soil. 2019, 435, 437-447. [CrossRef]

11. Darby, B.J.; Neher, D.A.; Housman, D.C.; Belnap, J. Few apparent short-term effects of elevated soil temperature and increased frequency of summer precipitation on the abundance and taxonomic diversity of desert soil micro- and meso-fauna. Soil Biol. Biochem. 2011, 43, 1474-1481. [CrossRef]

12. Reczuga, M.K.; Lamentowicz, M.; Mulot, M.; Mitchell, E.A.D.; Buttler, A.; Chojnicki, B.; Slowinski, M.; Binet, P.; Chiapusio, G.; Gilbert, D.; et al. Predator-prey mass ratio drives microbial activity under dry conditions in Sphagnum peatlands. Ecol. Evol. 2018, 8, 5752-5764. [CrossRef] [PubMed]

13. Yan, D.M.; Yan, D.H.; Song, X.S.; Yu, Z.L.; Peng, D.; Ting, X.; Weng, B.S. Community structure of soil nematodes under different drought conditions. Geoderma 2018, 325, 110-116. [CrossRef]

14. Belnap, J.; Phillips, S.L.; Sherrod, S.K.; Moldenke, A. Soil biota can change after exotic plant invasion: Does this affect ecosystem processes. Ecology 2005, 86, 3007-3017. [CrossRef]

15. Renco, M.; Balezentiene, L. An analysis of soil free-living and plant-parasitic nematode communities in three habitats invaded by Heracleum sosnowskyi in central Lithuania. Biol. Invasions 2015, 17, 1025-1039. [CrossRef]

16. Zhang, Y.Z.; Pennings, S.C.; Li, B.; Wu, J.H. Biotic homogenization of wetland nematode communities by exotic Spartina alterniflora in China. Ecology 2019, 100, e02596. [CrossRef] [PubMed]

17. Lazzaro, L.; Mazza, G.; d'Errico, G.; Fabiani, A.; Giuliani, C.; Inghilesi, A.F.; Lagomarsino, A.; Landi, S.; Lastrucci, L.; Pastorelli, R.; et al. How ecosystems change following invasion by Robinia pseudoacacia: Insights from soil chemical properties and soil microbial, nematode, microarthropod and plant communities. Sci. Total Environ. 2018, 622, 1509-1518. [CrossRef]

18. Qin, Z.; Xie, J.F.; Quan, G.M.; Zhang, J.E.; Mao, D.J.; Wang, J.X. Changes in the soil meso- and micro-fauna community under the impacts of oxotic Ambrosia artemisiifolia. Environ. Res. 2019, 34, 265-276. [CrossRef]

19. Cerevkova, A.; Miklisova, D.; Bobul'ska, L.; Renco, M. Impact of the invasive plant Solidago gigantea on soil nematodes in a semi-natural grassland and a temperate broadleaved mixed forest. J. Helminthol. 2019, 94, e15. [CrossRef]

20. Zhang, F.; Wan, F. Canada Goldenrod Solidago canadensis L. In Biological Invasions and Its Management in China; Springer: Singapore, 2017; pp. 143-151. [CrossRef]

21. Hu, Z.Y.; Li, J.T.; Shi, K.W.; Ren, G.Q.; Dai, Z.C.; Sun, J.F.; Zheng, X.J.; Zhou, Y.W.; Zhang, J.Q.; Li, G.L.; et al. Effects of Canada Goldenrod Invasion on Soil Extracellular Enzyme Activities and Ecoenzymatic Stoichiometry. Sustainability 2021, $13,3768$. [CrossRef]

22. Zhang, H.Y.; Goncalves, P.; Copeland, E.; Qi, S.S.; Dao, Z.C.; Li, G.L.; Wang, C.Y.; Du, D.L.; Thomas, T. Invasion by the weed Conyza canadensis alters soil nutrient supply and shifts microbiota structure. Soil Biol. Biochem. 2020, 143, 107739. [CrossRef]

23. Li, Q.W.; Liu, Y.; Gu, Y.F.; Guo, L.; Huang, Y.Y.; Zhang, J.; Xu, Z.F.; Tan, B.; Zhang, L.; Chen, L.H.; et al. Ecoenzymatic stoichiometry and microbial nutrient limitations in rhizosphere soil along the hailuogou glacier forefield chronosequence. Sci. Total Environ. 2020, 704, 135413. [CrossRef] [PubMed]

24. Murphy, J.; Riley, J.P. A modified single solution method for the determination of phosphate in natural waters. Anal. Chim. Acta. 1962, 27, 31-36. [CrossRef]

25. Olsen, S.R.; Sommers, L.E. Phosphorous. In Methods of Soil Analysis, Part 2, Chemical and Microbial Properties; SSSA and ASA: Madison, WI, USA, 1982; pp. 403-430.

26. Miranda, K.M.; Espey, M.G.; Wink, D.A. A rapid, simple spectrophotometric method for simultaneous detection of nitrate and nitrite. Nitric Oxide 2001, 5, 62-71. [CrossRef] [PubMed]

27. Mulvaney, R.L. Nitrogen-inorganic Forms. In Methods of Soil Analysis. Part 3, Chemical Methods; SSSA and ASA: Madison, WI, USA, 1996; pp. 1123-1184. 
28. Vance, E.D.; Brookes, P.C.; Jenkinson, D.S. An extraction method for measuring soil microbial biomass. C. Soil Biol. Biochem. 1987, 19, 703-707. [CrossRef]

29. Brookes, P.C.; Landman, A.; Pruden, G.; Jenkinson, D.S. Chloroform fumigation and the release of soil nitrogen: A rapid direct extraction method to measure microbial biomass nitrogen in soil. Soil Biol. Biochem. 1985, 17, 837-842. [CrossRef]

30. Viglierchio, D.R.; Schmitt, R.V. On the methodology of nematode extraction from field samples: Biermann funnel modifications. J. Nematol. 1983, 15, 438-444.

31. Bongers, T. The maturity index: An ecological measure of environmental disturbance based on nematode species composition. Oecologia 1990, 83, 14-19. [CrossRef] [PubMed]

32. Ferris, H.; Bongers, T.; de Goede, R.G.M. A framework for soil food web diagnostics: Extension of the nematode faunal analysis concept. Appl. Soil Ecol. 2001, 18, 13-29. [CrossRef]

33. Kitagami, Y.; Kanzaki, N.; Matsuda, Y. Distribution and community structure of soil nematodes in coastal Japanese pine forests were shaped by harsh environmental conditions. Appl. Soil Ecol. 2017, 119, 91-98. [CrossRef]

34. R Core Team. R: A Language and Environment for Statistical Computing; Vienna, Austria. 2013. Available online: https: / / www.R-project.org (accessed on 20 December 2020).

35. Stevnbak, K.; Scherber, C.; Gladbach, D.J.; Beier, C.; Mikkelsen, T.N.; Christensen, S. Interactions between above- and belowground organisms modified in climate change experiments. Nat. Clim. Chang. 2012, 2, 805-808. [CrossRef]

36. Castanho, A.D.A.; Coe, M.T.; Brando, P.; Macedo, M.; Baccini, A.; Walker, W.; Andrade, E.M. Potential shifts in the aboveground biomass and physiognomy of a seasonally dry tropical forest in a changing climate. Environ. Res. Lett. 2020, 15, 034053. [CrossRef]

37. Shi, Y.; Xiang, X.J.; Shen, C.C.; Chu, H.Y.; Neufeld, J.D.; Walker, V.K.; Grogan, P. Vegetation-Associated Impacts on Arctic Tundra Bacterial and Microeukaryotic Communities. Appl. Environ. 2015, 81, 492-501. [CrossRef] [PubMed]

38. Zhang, K.R.; Cheng, X.L.; Shu, X.; Liu, Y.; Zhang, Q.F. Linking soil bacterial and fungal communities to vegetation succession following agricultural abandonment. Plant Soil 2018, 431, 19-36. [CrossRef]

39. Chen, L.L.; Baoyin, T.; Minggagud, H. Effects of mowing regimes on above- and belowground biota in semi-arid grassland of northern China. J. Environ. 2021, 277, 111441. [CrossRef] [PubMed]

40. Song, S.S.; Zhang, C.; Gao, Y.; Zhu, X.Y.; Wang, R.H.; Wang, M.D.; Zheng, Y.L.; Hou, L.J.; Liu, M.; Wu, D.M. Responses of wetland soil bacterial community and edaphic factors to two-year experimental warming and Spartina alterniflora invasion in Chongming Island. J. Clean. Prod. 2020, 250, 119502. [CrossRef]

41. Zhang, G.G.; Sui, X.; Li, Y.; Jia, M.Q.; Wang, Z.W.; Han, G.D.; Wang, L.C. The response of soil nematode fauna to climate drying and warming in Stipa breviflora desert steppe in Inner Mongolia, China. J. Soils Sediments 2020, 20, 2166-2180. [CrossRef]

42. Li, G.; Kim, S.; Han, S.H.; Chang, H.; Du, D.L.; Son, Y. Precipitation affects soil microbial and extracellular enzymatic responses to warming. Soil Biol. Biochem. 2018, 120, 212-221. [CrossRef]

43. Zhang, Z.W.; Li, Q.; Zhang, H.Y.; Hu, Y.Y.; Hou, S.L.; Wei, H.W.; Yin, J.X.; Lu, X.T. The impacts of nutrient addition and livestock exclosure on the soil nematode community in a degraded grassland. Land Degrad Dev. 2019, 30, 1574-1583. [CrossRef]

44. Ma, Q.H.; Yu, H.Y.; Liu, X.D.; Xu, Z.Z.; Zhou, G.S.; Shi, Y.H. Climatic warming shifts the soil nematode community in a desert steppe. Clim. Chang. 2018, 150, 243-258. [CrossRef]

45. Peralta, G.; Schon, N.L.; Dickie, I.A.; St John, M.G.; Orwin, K.H.; Yeates, G.W.; Peltzer, D.A. Contrasting responses of soil nematode communities to native and non-native woody plant expansion. Oecologia 2019, 190, 891-899. [CrossRef]

46. Wei, M.; Wang, S.; Xiao, H.G.; Wu, B.D.; Jiang, K.; Du, D.L.; Wang, C.Y. Stand-alone or co-occurring invasive plant species do not modify the diversity of the soil N-2-fixing bacterial community. Plant Ecol Divers. 2020, 13, 277-287. [CrossRef]

47. Bongiorno, G.; Bodenhausen, N.; Bunemann, E.K.; Brussaard, L.; Geisen, S.; Mader, P.; Quist, C.W.; Walser, J.C.; de Goede, R.G.M. Reduced tillage, but not organic matter input, increased nematode diversity and food web stability in European long-term field experiments. Mol. Ecol. 2019, 28, 4987-5005. [CrossRef] [PubMed]

48. Anthony, M.A.; Stinson, K.A.; Moore, J.A.M.; Frey, S.D. Plant invasion impacts on fungal community structure and function depend on soil warming and nitrogen enrichment. Oecologia 2020, 194, 659-672. [CrossRef] [PubMed] 